www.jmscr.igmpublication.org

Impact Factor 5.244

Index Copernicus Value: 83.27

ISSN (e)-2347-176x ISSN (p) 2455-0450

crossref DOI:_http://dx.doi.org/10.18535/jmscr/v4i9.73

Journal Of Medical Science And Clinical Research

\title{
How healthy are Health Professionals? Health Related Quality of Life of Doctors and Paramedics at a Tertiary Care Hospital in India
}

\author{
Authors \\ Varsha J. Patel ${ }^{1}$, Hemant Tiwari ${ }^{2}$, Chirag Vaghela ${ }^{3}$ \\ ${ }^{1}$ Chairperson, Research Department, Dr. Jivraj Mehta Smarak Health Foundation, Bakeri Medical Research \\ Centre, Ahmedabad-380007, Gujarat State, India \\ Email:drvarsha4@ rediffmail.com \\ ${ }^{2}$ Assistant Professor, Dept of Community Medicine, NHL Municipal Medical College, Ahmedabad- 380006 \\ Email: tiwarihemant1@ @ediffmail.com \\ ${ }^{3}$ Research Coordinator, Research Department, Dr. Jivraj Mehta Smarak Health Foundation, Bakeri Medical \\ Research Centre, Ahmedabad-380007, Gujarat State, India \\ Email:chvaghela10@gmail.com
}

\begin{abstract}
Background \& objectives: Health and quality of life of health personnel significantly influences optimum functioning of any health care service. This study assessed the Health related quality of life (HRQoL) of health personnel at a tertiary care hospital in India.

Methods: We assessed HRQoL of doctors, nurses and health technicians using EQ 5D-5L. Demographic details and presence of stress and health problem were noted. Respondents answered the EQ 5D-5L questionnaire by selecting appropriate level from 1-no problem to 5- severe problem for five dimensionsMobility, self-care, usual activity, pain/discomfort and anxiety/depression. They also selected their overall health level on EQ VAS scale from 0-worst possible to 100-best possible health. Data was analysed to assess scores for each dimensions, EQ VAS score and EQ-5D-5L Crosswalk Index.

Results: Total 272 health personnel participated with 126 doctors and 146 paramedics. Mean age was $37.77 \pm 15.68$ with $45 \%$ male participants. Of five dimensions of EQ 5D-5L, $100 \%$ reported level 1(no problem) for self- care while $88.82 \%$ of doctors and $83.56 \%$ paramedics reported level 1 for pain/discomfort. EQ VAS did not differ significantly between male and female $(P=0.215)$. Mean EQ VAS score for doctors and paramedics was $90.225 \pm 8.0191$ and $90.593 \pm 8.129(P=0.7072)$ respectively. Mobility, pain/discomfort and anxiety inversely correlated with EQ VAS score. Presence of stress and health problem inversely correlated with EQ VAS score.

Interpretation \& Conclusions: The study suggests reasonably good health related quality of life of health personnel at JMSHF. Age is not a predictor of HRQoL. Stress and health problem negatively influence HRQoL. EQ 5D-5L is a reliable instrument for measuring HRQoL in our set up.

Key Words- Health personnel, Health status, HRQoL, EQ 5D-5L, Quality of life.
\end{abstract}

\section{INTRODUCTION}

According to the World Health Organization (WHO), Quality of life is 'an individual's perception of their position in life in the context of the culture and value systems in which they live, and in relation to their goals, expectations, standards and concerns, ${ }^{\text {[1]. }}$ Researchers have conceptualized quality of life on many levels, and there are multiple 
views on how it should be defined and measured. The health community has generally chosen to focus on the individual-level aspects of quality of life that can be shown to affect physical and mental health. This narrower concept is referred to as healthrelated quality of life (HRQoL). ${ }^{[2]}$ Two types of tools have been developed to measure HRQoL. Generic tools are general purpose measures used to assess HRQoL of communities and also for comparison between populations. Disease specific tools focus on particular disease and can be useful for assessing treatment effectiveness. WHO BREF ${ }^{[3]}$ and SF $36^{[4]}$ are among the widely used generic tools. However these are long questionnaires with many questions and thus time consuming.

EQ-5D is a standardized measure of health status developed by the Euro Qol Group in order to provide a simple, generic measure of health for clinical and economic appraisal1.The EQ-5D-5L consists of 2 pages - the EQ-5D-5L descriptive system and the EQ Visual Analogue scale (EQ VAS) (The descriptive system comprises the 5 dimensions (mobility, self-care, usual activities, pain/ discomfort, anxiety/depression). Each dimension has 5 levels: no problems, slight problems, moderate problems, severe problems, and extreme problems. The respondent is asked to indicate his/her health state by ticking (or placing a cross) in the box against the most appropriate statement in each of the 5 dimensions. This decision results in a 1-digit number expressing the level selected for that dimension. The digits for 5 dimensions can be combined in a 5-digit number describing the respondent's health state. ${ }^{[5]}$

It is important for the doctors and other health personnel to stay healthy so that the health care system in which they function performs at optimum level. When physicians are unwell, the performance of health-care systems can be suboptimum. ${ }^{[6]}$ It is important to assess the QOL of Health professionals working at hospital as they are exposed to stress and also may have chronic diseases. There is limited data regarding health status of health personnel. ${ }^{\text {[7-9] }}$ Hence this study was undertaken with the aim to assess the health status and HRQoL of health personnel including doctors, physiotherapists, nurses and technicians at of Dr. Jivraj Mehta Smarak Health Foundation \& Bakeri Medical Research Centre (JMSHF), a tertiary care multispecialty hospital. EQ-5D-5L developed by Euro Quol group was selected as it is validated, used widely and is less time consuming due to its brevity. [4]

\section{METHOD}

\section{Objective}

To assess the quality of life of health personnel working at Dr. Jivraj Mehta Smarak Health Foundation, a tertiary care hospital in Ahmedabad in Gujarat State of India Using EQ-5D-5L(5)

\section{Inclusion criteria -}

1. Full time and Consultant doctors of JMSHF including physiotherapists

2. Nursing staff

3. Technicians indifferent health departments Exclusion criteria- Administrative personnel Study Design- Cross-sectional descriptive study After obtaining approval from Institutional Ethics Committee of JMSHF, data was collected by one of the authors using EQ-5D-5L questionnaire (English version $1 \mathrm{UK})^{[10]}$ from doctors, nursing staff and health technicians working at JMSHF. Data regarding demographic details, speciality, experience, presence of stress, any health problem etc. was also collected.

The EQ-5D-5L consists of 2 parts - the EQ-5D-5L descriptive system and the EQ Visual Analogue scale (EQ VAS). The descriptive system comprises the 5 dimensions (mobility, self-care, usual activities, pain/discomfort, anxiety /depression). Each dimension has 5 levels: no problems, slight problems, moderate problems, severe problems, and extreme problems. The respondent was asked to indicate his/her health state by ticking in the box against the most appropriate statement in each of the 5 dimensions. This decision results in a 1-digit number expressing the level selected for that dimension.

The EQ VAS records the respondent's self-rated health on a $20 \mathrm{~cm}$ vertical, visual analogue scale from 0 to 100 , with endpoints labeled the best health you can imagine' and 'the worst health you 
can imagine'. This information provides a quantitative measure of health as judged by the individual respondents. The investigator asked respondents to 'mark an $\mathrm{X}$ on the scale to indicate how your health is TODAY' and then to 'write the number you marked on the scale in the box below'. [10]

EQ-5D-5L Crosswalk Index was calculated with the help of EQ-5D-5L Crosswalk Index Value Calculator' downloaded from the EuroQol website. [11]

Data was analysed to find EQ-5D-5L scores for 5 dimensions, EQ VAS scores for these groups. Data was analysed using SPSS version 20 (IBM).

\section{RESULTS}

Total 272 out of $306(89 \%)$ health personnel participated with 126 doctors and 146 paramedical staff. Overall mean age was $37.77 \pm 15.68$ years while mean age of doctors and paramedics was 42.57 \pm 17.39 and $31.51 \pm 10.66$ years respectively. There was no significant difference in mean age between two groups $(P=1.97)$.

Out of 272, 123 were male participants. Out of 146 paramedics, 122were nurses and rest were technicians. Health problems were reported by 47 respondents including 28 doctors. There was no significant difference for job experience between two groups $(P=1.02)$. (Table 1$)$

\section{EQ-5D-5L scores}

Table 2 shows percent of doctors reporting EQ 5D levels 1 to 5 by dimensions and age group. Maximum i.e. $100 \%$ reported level 1(no problem) for self- care dimension while $88.82 \%$ of respondents reported level 1 for pain/discomfort dimension.

Table 3 shows distribution of percent of paramedics reporting EQ 5D levels 1 to 5 by dimensions and age group. Self care was reported at level 1 by $100 \%$ while pain/discomfort scored lowest at $83.56 \%$ for the same.

\section{EQ VAS score}

Mean VAS score for male (123) and female (149) health professionals was $90.12 \pm 8.68$ and 91.36 \pm 7.54 respectively. There was no significant difference between the two groups. $(\mathrm{P}=0.215)$
Figure 1and 2 display Mean EQ VAS scores according to age group and sex for doctors (126) and for paramedics (146) respectively. Mean EQ VAS score for doctors was 90.225 \pm 8.0191 , while for paramedics EQ VAS was $90.593 \pm 8.1291$. There was no significant difference between mean scores of doctors and paramedics $(P=0.7072)$ There was a significant difference in EQ VAS score between male and female doctors $(P=0.0123)$ with female doctors reporting higher score while no significant difference was seen between male and female paramedics $(P=0.084722)$.

For all health personnel (272), of the five domains of EQ 5D-5L, mobility $\left(\mathrm{r}_{\mathrm{s}}=-.149, \quad P<0.05\right)$, pain/discomfort $\left(\mathrm{r}_{\mathrm{s}}=-.189, P<0.01\right)$ and anxiety. $\left(\mathrm{r}_{\mathrm{s}}\right.$ $=-0.284, P<0.01$ ) were inversely correlated with EQ VAS score. There was negative correlation between presence of stress and health problem and EQ VAS score $\left(\mathrm{r}_{\mathrm{s}}=-0.134, \quad P<0.05\right.$ and $\mathrm{r}_{\mathrm{s}}=-$ 0.124, $\quad P<0.05$ respectively). For paramedical personnel (146), mobility $\left(\mathrm{r}_{\mathrm{s}}=-.169, \mathrm{P}<.05\right)$, usual activity $\left(\mathrm{r}_{\mathrm{s}}=-.180, \mathrm{P}<0.05\right)$, pain/discomfort $\left(\mathrm{r}_{\mathrm{s}}=-\right.$ $.248, \mathrm{P}<0$.01) and anxiety/depression $\left(\mathrm{r}_{\mathrm{s}}=-.262\right.$, $\mathrm{P}<.01)$ showed significant inverse correlation with EQ VAS score. Presence of stress also negatively correlated with EQ VAS score $\mathrm{r}_{\mathrm{s}}=-.171, \mathrm{P}<0.05$ ). Age, sex and presence of health problem had no significant correlation with VAS score.

For doctors single dimension having significant and negative correlation with VAS score was anxiety $\left(\mathrm{r}_{\mathrm{s}}\right.$ $=-.307, \mathrm{P}<0.01)$. Age, sex, presence of health problem or stress did not show significant correlation with VAS score.

Mean EQ-5D-5L Crosswalk Index was 0.958 for all health personnel, 0.962 for doctors and 0.954 for paramedics. Cronbach alpha values for EQ-5D-5L were- All health personnel- .726, Doctors- .716 and Paramedics- .766. 
Table 1 Characteristics of study population $(\mathrm{N}=272)$

\begin{tabular}{|l|l|l|l|}
\hline Character & Doctors & Paramedical & Total \\
\hline Number & 126 & 146 & 272 \\
MEAN AGE \pm SD $(\mathbf{y r s})$ & $42.57 \pm 17.39$ & $31.51 \pm 10.66$ & $37.77 \pm$ \\
GENDER & & & 15.68 \\
$\begin{array}{l}\text { Male } \\
\text { Female }\end{array}$ & 87 & 36 & 123 \\
CATEGORY & 39 & 110 & 149 \\
& Medical officer-49 & Nurses-122 & - \\
EXPERIENCE \pm SD(YRS) & Specialist/subspecialist- 77 & Technicians-24 & - \\
& $18.43 \pm 15.80$ & $8.25 \pm 8.69$ & $12.92 \pm$ \\
Presence of HEALTH PROBLEM & 28 & 18 & 13.44 \\
STRESS & 55 & 21 & 46 \\
\hline
\end{tabular}

Table 2 Percent of doctors reporting EQ 5D-5L levels 1 to 5 by dimensions and age grou

\begin{tabular}{|l|l|l|l|l|l|l|l|}
\hline \multirow{2}{*}{ Dimension } & \multicolumn{9}{l}{ Age group } & \multirow{2}{*}{ Total } \\
\cline { 2 - 7 } & $\mathbf{2 1 - 3 0}$ & $\mathbf{3 1 - 4 0}$ & $\mathbf{4 1 - 5 0}$ & $\mathbf{5 1 - 6 0}$ & $\mathbf{6 1 - 7 0}$ & $\begin{array}{l}\mathbf{7 1} \\
\text { upwards }\end{array}$ & \\
\hline Mobility- & & & & & & \\
Level 1 & 93.54 & 100 & 96.0 & 100 & 84.62 & 84.62 & 94.44 \\
Level 2 & 06.45 & 0.0 & 4.0 & 0.0 & 7.69 & 15.38 & 4.76 \\
Level 3 & 0.0 & 0.0 & 0.0 & 0.0 & 7.69 & 0.0 & 0.8 \\
Level 4 & 0.0 & 0.0 & 0.0 & 0.0 & 0.0 & 0.0 & 0.0 \\
Level 5 & 0.0 & 0.0 & 0.0 & 0.0 & 0.0 & 0.0 & 0.0 \\
\hline Self care - & & & & & & & \\
Level 1 & 100 & 100 & 100 & 100 & 100 & 100 & 100 \\
Level 2 & 0.0 & 0.0 & 0.0 & 0.0 & 0.0 & 0.0 & 0.0 \\
Level 3 & 0.0 & 0.0 & 0.0 & 0.0 & 0.0 & 0.0 & 0.0 \\
Level 4 & 0.0 & 0.0 & 0.0 & 0.0 & 0.0 & 0.0 & 0.0 \\
Level 5 & 0.0 & 0.0 & 0.0 & 0.0 & 0.0 & 0.0 & 0.0 \\
\hline Usual activity- & & & & & & & \\
Level 1 & 87.1 & 100 & 100 & 100 & 100 & 100 & 97.85 \\
Level 2 & 12.9 & 0.0 & 0.0 & 0.0 & 0.0 & 0.0 & 2.15 \\
Level 3 & 0.0 & 0.0 & 0.0 & 0.0 & 0.0 & 0.0 & 0.0 \\
Level 4 & 0.0 & 0.0 & 0.0 & 0.0 & 0.0 & 0.0 & 0.0 \\
Level 5 & 0.0 & 0.0 & 0.0 & 0.0 & 0.0 & 0.0 & 0.0 \\
\hline Pain/discomfort- & & & & & & & \\
Level 1 & 87.1 & 88.88 & 80.0 & 100 & 76.92 & 100 & 88.82 \\
Level 2 & 12.9 & 11.12 & 20.0 & 0.0 & 23.08 & 0.0 & 11.18 \\
Level 3 & 0.0 & 0.0 & 0.0 & 0.0 & 0.0 & 0.0 & 0.0 \\
Level 4 & 0.0 & 0.0 & 0.0 & 0.0 & 0.0 & 0.0 & 0.0 \\
Level 5 & 0.0 & 0.0 & 0.0 & 0.0 & 0.0 & 0.0 & 0.0 \\
\hline Anxiety/depression- & & & & & & & \\
Level 1 & 83.87 & 81.48 & 92.0 & 94.12 & 100 & 100 & 91.92 \\
Level 2 & 16.13 & 18.52 & 08.0 & 05.88 & 0.0 & 0.0 & 8.08 \\
Level 3 & 0.0 & 0.0 & 0.0 & 0.0 & 0.0 & 0.0 & 0.0 \\
Level 4 & 0.0 & 0.0 & 0.0 & 0.0 & 0.0 & 0.0 & 0.0 \\
Level 5 & 0.0 & 0.0 & 0.0 & 0.0 & 0.0 & 0.0 & 0.0 \\
\hline
\end{tabular}


Table 3 Percent of paramedics reporting EQ 5D-5L levels 1 to 5 by dimensions and age group

\begin{tabular}{|c|c|c|c|c|c|c|}
\hline \multirow[t]{2}{*}{ Dimension } & \multicolumn{5}{|c|}{ Age group } & \multirow{2}{*}{ Total } \\
\hline & $21-30$ & $31-40$ & $41-50$ & $51-60$ & 61-70 & \\
\hline \multicolumn{7}{|l|}{ Mobility- } \\
\hline Level 1 & 95.65 & 86.36 & 100 & 92.31 & 100 & 94.52 \\
\hline Level 2 & 2.17 & 13.63 & 0.0 & 0.0 & 0.0 & 4.1 \\
\hline Level 3 & 2.17 & 0.0 & 0.0 & 7.69 & 0.0 & 1.4 \\
\hline Level 4 & 0.0 & 0.0 & 0.0 & 0.0 & 0.0 & 0.0 \\
\hline Level 5 & 0.0 & 0.0 & 0.0 & 0.0 & 0.0 & 0.0 \\
\hline Self care -Level 1 & 100 & 100 & 100 & 100 & 100 & 100 \\
\hline Level 2 & 0.0 & 0.0 & 0.0 & 0.0 & 0.0 & 0.0 \\
\hline Level 3 & 0.0 & 0.0 & 0.0 & 0.0 & 0.0 & 0.0 \\
\hline Level 4 & 0.0 & 0.0 & 0.0 & 0.0 & 0.0 & 0.0 \\
\hline Level 5 & 0.0 & 0.0 & 0.0 & 0.0 & 0.0 & 0.0 \\
\hline Usual activity-Level 1 & 98.91 & 95.45 & 100 & 100 & 100 & 98.63 \\
\hline Level 2 & 1.09 & 4.55 & 0.0 & 0.0 & 0.0 & 1.37 \\
\hline Level 3 & 0.0 & 0.0 & 0.0 & 0.0 & 0.0 & 0.0 \\
\hline Level 4 & 0.0 & 0.0 & 0.0 & 0.0 & 0.0 & 0.0 \\
\hline Level 5 & 0.0 & 0.0 & 0.0 & 0.0 & 0.0 & 0.0 \\
\hline \multicolumn{7}{|l|}{ Pain/discomfort- } \\
\hline Level 1 & 90.21 & 77.27 & 64.71 & 76.92 & 50.0 & 83.56 \\
\hline Level 2 & 9.78 & 22.73 & 29.41 & 15.38 & 0.0 & 13.04 \\
\hline Level 3 & 0.0 & 0.0 & 0.0 & 0.0 & 50.0 & 0.68 \\
\hline Level 4 & 0.0 & 0.0 & 5.88 & 7.7 & 0.0 & 2.74 \\
\hline Level 5 & 0.0 & 0.0 & 0.0 & 0.0 & 0.0 & 0.0 \\
\hline \multicolumn{7}{|l|}{ Anxiety/depression- } \\
\hline $\begin{array}{l}\text { Level } 1 \\
\text { Level } 2\end{array}$ & $\begin{array}{l}92.39 \\
7.61\end{array}$ & $\begin{array}{l}90.91 \\
9.09\end{array}$ & $\begin{array}{l}94.12 \\
5.88\end{array}$ & $\begin{array}{l}92.30 \\
7.7\end{array}$ & $\begin{array}{l}100 \\
0.0\end{array}$ & $\begin{array}{l}91.78 \\
8.22\end{array}$ \\
\hline Level 3 & 0.0 & 0.0 & 0.0 & 0.0 & 0.0 & 0.0 \\
\hline Level 4 & 0.0 & 0.0 & 0.0 & 0.0 & 0.0 & 0.0 \\
\hline Level 5 & 0.0 & 0.0 & 0.0 & 0.0 & 0.0 & 0.0 \\
\hline
\end{tabular}

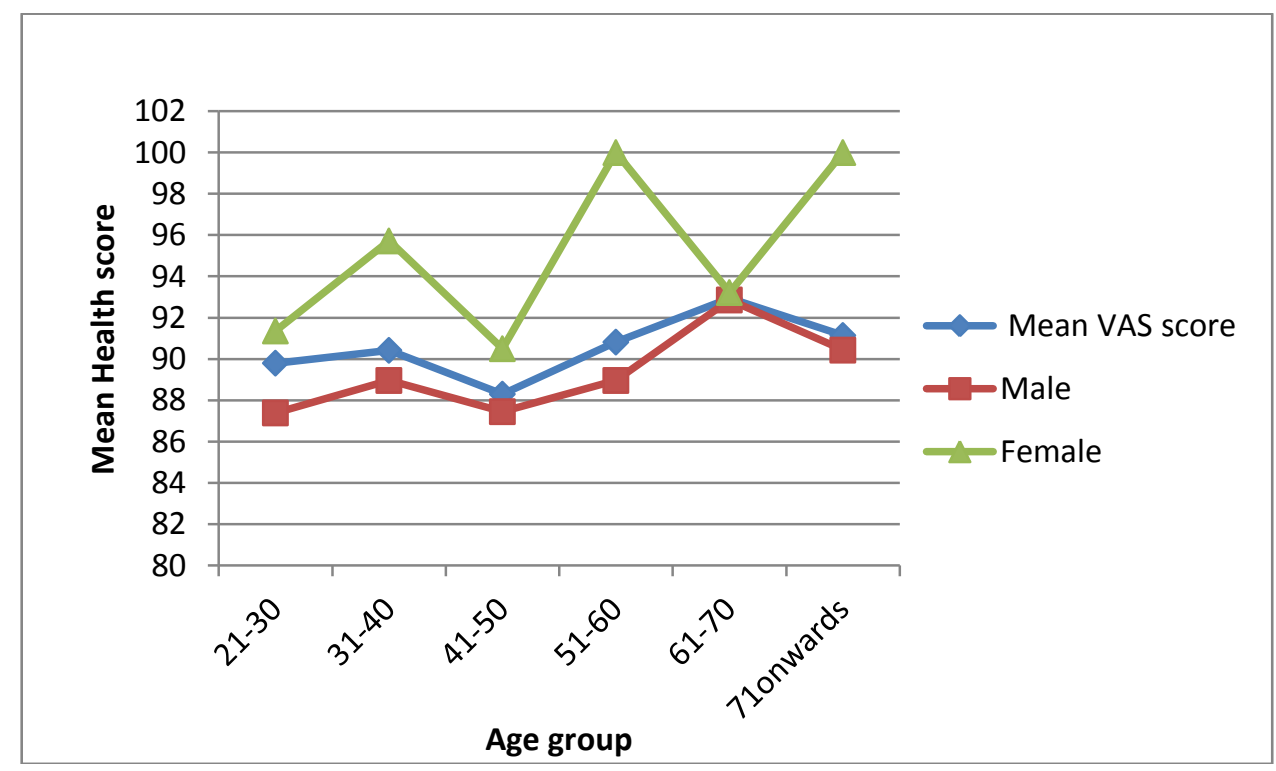

Figure 1 Doctors- Mean EQ VAS scores by age group and sex $(\mathrm{N}=126)$ 


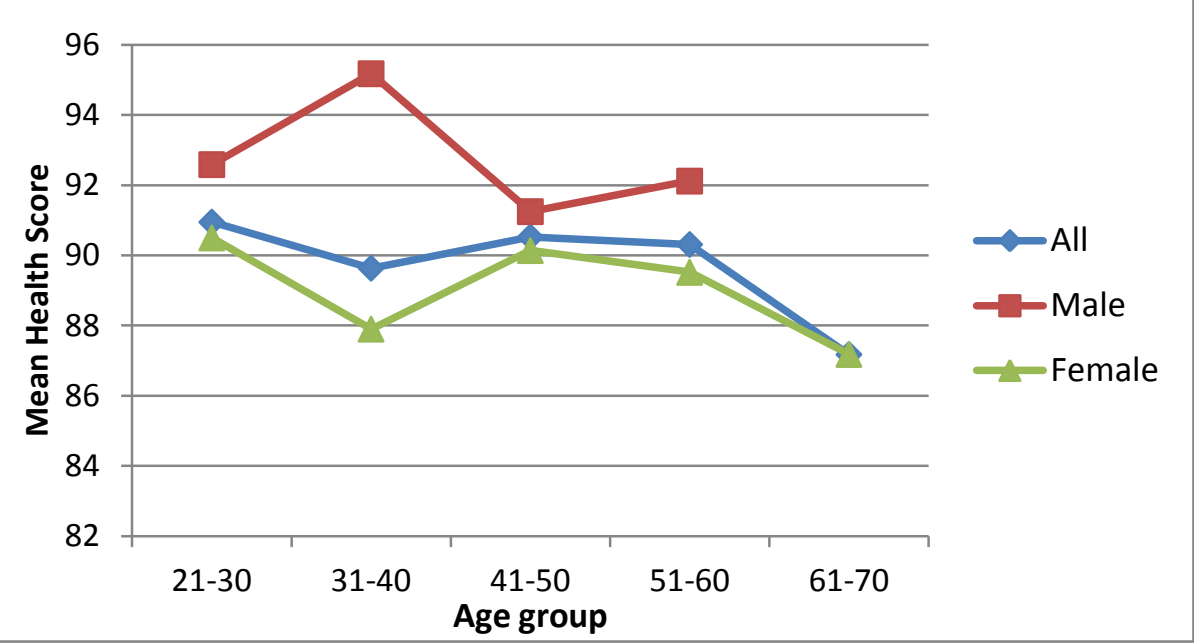

Figure 2 Paramedics-Mean EQ VAS scores by age group and sex $(\mathrm{N}=146)$

\section{DISCUSSION}

This cross sectional study aimed at assessing health status of health professionals of a tertiary care multi-speciality hospital. Health personnel are known to face greater stress than general population due to the working conditions. $[6,12]$ In our study $76(28 \%)$ health personnel reported stress with 55 of 126( 44\%) doctors and 21( $15 \%)$ of paramedics. Thus a greater brunt of stress is borne by doctors than paramedics. These are lower than previous studies reporting stress in $73.59 \%$, and $37.8 \%$ of the nurses. ${ }^{[12.13]}$ On the other hand $16.9 \%$ in doctors of UK while $46 \%$ of physicians surveyed in one study reported medical practice to be very or extremely stressful compared to $44 \%$ in our study. ${ }^{[14,15]}$ All the doctors reporting stress were consultants in different specialities. Age groups 31 to $40(56 \%)$ and 41 to $50(68 \%)$ are more vulnerable in this respect. Young doctors are reported to have stress and burnout in previous studies also. ${ }^{[16]}$ This period is for moving the individual career graph upward and finally settling at some level. Social and family affairs including marriage, children add to the stress.

Previous studies reported $44 \%$ doctors having chronic health problems ${ }^{[17]}$ and $34 \% ; 23 \%$ nurses reporting illness. ${ }^{[18]}$ In our study 28 (22\%) doctors and $18(12.3 \%)$ paramedics with 14 of 123 (11.4\%) nurses and 4 of 23 technicians(17.4\%) had health problems, lower than reported elsewhere.
For the EQ 5D-5L reporting level 1 in all 5 dimensions would mean healthy quality of life. Considering this 219 of $272(80.5 \%)$ of health personnel, 111 of $146(76 \%)$ paramedics and 108 of 126(85.7\%) doctors reported optimum HRQoL. EQ VAS score representing perception of health on a scale of 1 to 100 is also higher for doctors than paramedics. The cross walk index value is 0.957 for all health personnel, 0.963 for doctors and lower 0.953 for paramedics. The reasons for somewhat inferior although not statistically different health of paramedics can be most of them are female nurses having family responsibilities, with lower income than doctors and able to pay less attention for health care in addition to work pressure.

Interesting finding of this study is better HRQoL in female doctors compared to male doctors in all age groups. This is in contrast to previous reports wherein female doctors reported poorer quality of life than males ${ }^{[7,16]}$

Out of five domains of EQ 5D-5L self care scored highest with all respondents selecting level 1 that is no problem while pain/discomfort and anxiety/ depression scored lower than others. Previous studies of health personnel using different measuring tools also reported poorer scores for pain and mental/emotional domains. ${ }^{[7,16,19,20]}$ No participant reported problem with self-care. Obviously this group is leading active life which is not possible with any disease/deformity that 
interferes with self care. Stress and presence of health problem showed inverse relation with EQ VAS score. Problems related to mobility, pain/ discomfort and anxiety also were inversely correlated with EQ VAS score. These findings corroborate previous studies reporting low scores for bodily pain and mental health. ${ }^{[7,19]}$ Here it should be noted that none of the previous studies assessing HRQoL of health personnel have used different tools with differing number and types of domains. Hence comparison cannot be accurately made.

Cronbach alpha values for EQ 5D-5L were greater than 0.7 for all health personnel, for doctors and for paramedics. This suggests good reliability of the tool for measuring HRQoL in these groups. It is brief and simple to use by both the researcher and participants.

The limitation of the study is the results cannot be generalised as they represent only one health care set up. There is no study reporting health of Indian population with EQ 5D-5L and hence comparison with general population is not possible. However this is the first study reporting health related quality of life of health personnel at a tertiary care health set up in India.

\section{CONCLUSIONS}

The study reveals health status of doctors and paramedical staff at multi speciality hospital using EQ 5D-5L as a tool for measurement. Doctors and paramedics report good HRQoL. Among the five dimensions of EQ 5D-5L, anxiety/depression, pain/discomfort and mobility significantly affect the health status in this population. Age and sex do not influence health significantly while health problem and stress have adverse influence on HRQoL. Measures to relieve/ reduce stress can improve the quality of life of health personnel.

\section{ACKNOWLEDGEMENT}

We thank Dr. Paresh Parikh, Medical Superintendent of Dr. Jivraj Mehta Smarak Health Foundation \& Bakeri Medical Research Centre (JMSHF) for permission to undertake this study.
We are thankful to all clinicians and paramedical staff for their cooperation.

\section{REFERENCES}

1. WHOQOL Group. Development of the WHOQOL: Rationale and current status. Int J Mental Health 1994; 23: 24-56

2. Mielenz T, Jackson E, Currey S, DeVellis $\mathrm{R}$, Callahan LF. Psychometric properties of the Centers for Disease Control and Prevention Health-Related Quality of Life (CDC HRQOL) items in adults with arthritis. Health and Quality of Life Outcomes. 2006;4:66. doi:10.1186/14777525-4-66.

3. WHOQOL Group. Development of the World Health Organization WHOQOLBREF quality of life assessment. Psychol Med 1998b; 28: 551-558.

4. John E. WareSF-36® Health Survey Update,http://www.sf-

36.org/tools/sf36.shtml

5. Herdman M, Gudex C, Lloyd A, Janssen MF, Kind P, Parkin D, Bonsel G, Badia X. Development and preliminary testing of the new five-level version of EQ-5D (EQ-5D5L). Quality of Life Research.

6. Wallace JE, Lemaire JB, Ghali WA. Physician wellness: a missing quality indicator. Lancet. 2009;374(9702):17141721-cross reference)

7. Tountas Y, Demakakos PT, fantopoulos Y, Aga J, Houliara L, Pavi E. The health related quality of life of the employees in the Greek hospitals: assessing how healthy are the health workers.Health Qual Life Outcomes. 2003 Oct 27;1:61- 68

8. Guler N, Kuzu F. The health-related quality of life of the health professionals working in the primary healthcare centers and its correlation with selected sociodemographic factors in Sivas, a central Anatolian city. Scientific Research and Essay 2009, Vol.4 (12), pp. 1547-1552

9. Lindo JL, LaGrenade J, McCaw-Binns A, Eldemire-Shearer D. Health status and 
health maintenance practices among doctors and nurses at two hospitals in Jamaica West Indian Med J. 2009; 58(6):539-45

10. http://www.euroqol.org/fileadmin/user_upl oad/Documenten/PDF/Products/Sample_U K_English_EQ-5D-5L_Paper_Self_c omplete_v1.0_ID_24700_.pdf

11. http://www.euroqol.org/newslist/article/interim-scoring-for-the-eq-5d-51eq-5d-5l-crosswalk-index-valuecalculator.html

12. Kane PP. Stress causing psychosomatic illness among nurses. Indian $J$ Occup Environ Med 2009;13;1:28-32

13. Salilih S Z, Abajobir A. Work-Related Stress and Associated Factors among Nurses Working in Public Hospitals of Addis Ababa, Ethiopia: A Cross-Sectional Study, Workplace Health Saf. 201462 ; $8: 326-332$

14. McManus I C, Winder B C, G o r d o n D, Are UK doctors particularly stressed? LANCET $1999354,1358-9$

15. Henry J. OMA membership survey results confirm overwhelming level of frustration among Ontario physicians. Ont Med Rev 2004;71: 1-6

16. Liang Y, Wang H, Tao X. Quality of life of young clinical doctors in public hospitals in China's developed cities as measured by the Nottingham Health Profile (NHP). International Journal for Equity in Health. 2015. 14:85-96

17. Kay MP, Mitchell G K, Del Mar C B. Doctors do not adequately look after their own physical health. MJA 2004; 181: 368370-Cross ref

18. Jathanna PN, D'Silva J. Quality of life among nurses working in different health care setting in the state of Karnataka, India. CHRISMED J Health Res 2014;1:241-4
19. Silva AA, de Souza JM, da Silva Borges FN, Fischer FM, Health-related quality of life and working conditions among nursing providers. Rev Saúde Pública 2010; 44 (4):718-25

20. Hui-Ling H, Lun-Hui H, Mei-Hsiang L. Factors Related to Health Status among Nurses in Taiwan American Scientific Research Journal for Engineering, Technology, and Sciences (ASRJETS) (2016) 16, 1, 310-318 